\title{
Dress, gender and the embodiment of age: men and masculinities
}

\author{
Julia Twigg \\ School of Social Policy, Sociology and Social Research, University of Kent, Canterbury, UK \\ Email: j.m.twigg@kent.ac.uk
}

(Accepted 6 June 2018; first published online 31 August 2018)

\begin{abstract}
The study explores the role of clothing in the constitution of embodied masculinity in age, contrasting its results with an earlier study of women. It draws four main conclusions. First that men's responses to dress were marked by continuity both with their younger selves and with mainstream masculinity, of which they still felt themselves to be part. Age was less a point of challenge or change than for many women. Second, men's responses were less affected by cultural codes in relation to age. Dress was not, by and large, seen through the lens of age; and there was not the sense of cultural exile that had marked many of the women's responses. Third, for some older men dress could be part of wider moral engagement, expressive of values linked positively to age, embodying old-fashioned values that endorsed their continuing value as older men. Lastly, dress in age reveals some of the ways in which men retain aspects of earlier gender privilege. The study was based on qualitative interviews with 24 men aged 58-85, selected to display a range in terms of social class, occupation, sexuality, employment and relationship status. It forms part of the wider intellectual movement of cultural gerontology that aims to expand the contexts in which we explore later years; and contributes to a new focus on materiality within sociology.
\end{abstract}

Keywords: dress; fashion; embodiment; masculinities; gender; materiality

\section{Introduction}

Clothes mediate between the body and the social world. They are part of how notions of identity are grounded in the visual, one of the ways whereby social expectations act upon and are made manifest materially and culturally (Tseëlon, 1995; Entwistle, 2000). We are accustomed to such analyses in relation to gender, class, ethnicity, sexuality but not, until recently, to age. In an earlier study, I addressed these themes in relation to women and age (Twigg, 2013). This article continues the analysis with an exploration of the contrasting experiences of men.

It is sometimes thought that men - particularly older men - are indifferent to dress. Under the label of 'fashion' this can be true; and there are - as we shall see - systematic

(C) Cambridge University Press 2018 
cultural inhibitions in this area. Clothes, however, are a universal social phenomenon: no society leaves the body unmarked or unadorned (Entwistle, 2000). Shifting the analysis away from 'fashion' towards clothing and dress enables us to explore how these are everyday body practices engaged in by all, opening up aspects of embodied masculinity in age that have been overlooked.

This study reflects a larger movement within age studies, characterised as cultural gerontology (Twigg and Martin, 2015), that aims to shift the focus of analysis away from an exclusive attention to frailty, decline and its implications for public policy, towards an analysis that encompasses the experiences of getting older in a wider way, drawing in different subject matter and research traditions. It is also part of a new academic focus on materiality: the ways in which material objects - in this case clothes - operate within the social world, giving shape and meaning to the actions of daily life (Guy et al., 2001; Hird, 2004; Weber and Mitchell, 2004; Küchler and Miller, 2005; Ekerdt, 2009, 2015; Smith and Ekerdt, 2011; Buse et al., 2018). Earlier work explored the materiality of dress in the lives of people with dementia, including men (Buse and Twigg, 2014). This study explores its role in the lives of mainstream men over 58.

The article explores the responses of older men to the question of dress and its relationship to age. In doing so it contrasts their responses with ones made earlier by older women (Twigg, 2013). The differential character of these responses were the product of the intersection of two elements: the different cultural meanings of dress for men compared with women; and the different meanings and experiences of embodiment. How these operate in relation to age are the subject of this article.

\section{Masculinities and age}

Though often criticised for being monolithic and over-normative, Connell's pioneering account of masculinities remains the starting point for work in the field. Hegemonic masculinity represents the 'culturally most honoured way of being a man' (Connell, 1995; Connell and Messerschmidt, 2005: 832), and while not necessarily the lived form, is the most powerful and dominant script, guiding men's gendered lives. To a significant degree, hegemonic masculinity is defined relationally, constructed against women and gay men; and it exists in a hierarchically defined relationship with other masculinities, which represent subordinated and complicit forms. Initially this account of masculinity was not extended to old age. Other social divisions and their intersections were explored, but not age. Work on gender from within social gerontology tended, as part of the wider flowering of work influenced by feminism, to focus on women, with the result that older men remained relatively invisible (Greer, 1991; Woodward, 1999; Friedan, 1993; Ginn and Arber, 1995; Furman, 1997, 1999; Bartky, 1999; Twigg, 2004; Gullette, 2011). More recently, however, there have been a number of empirical studies that have explored the nature of masculinities in age (Thompson, 1994, 2006; Hearn, 1995; Marshall and Katz, 2002; Drummond, 2003; Katz and Marshall, 2003; Calasanti, 2004; Calasanti and King, 2005, 2007; Jones and Pugh, 2005; Hoonaard, 2007; Slevin, 2008; Tarrant, 2010; Pietiä and Ojala, 2011; Sandberg, 2011; Calasanti et al., 2013; Simpson, 2013a, 2013b; Hurd Clarke et al., 2014; Hearn and Wray, 2015; Jackson, 2016). 
Early work presented ageing as a fundamentally degendering process, eroding masculinity and producing an implicitly androgynous experience of old age. Idealised or hegemonic masculinity was associated with virility, physical strength and leadership, though tempered by qualities of civility; age by contrast threatened this (Hurd Clarke, in press). Age was seen to swamp gender in later years; and this linked to analyses of age that saw it as a process of segregation and homogenisation, in which the varied scripts of earlier years became a single, monolithic and objectifying one (Hazan, 1994).

More recently, however, work has challenged this over-simple account. Hearn and Wray (2015) argue that hegemonic masculinity, with its focus on the young, fails to engage adequately with the contradictory mixture of privilege, pain, power and fragility found in ageing men's lives. Jackson (2016) agrees that hegemonic masculinity is too weak to take on the uncertainties of ageing, and it misses the complexity of men's responses, which can involve intricate negotiation with new elements of masculinity, or at least new reflexive positionings. Though the hegemonic scripts of masculinity may, as Spector-Mersel (2006) argues, be truncated, arrested at the earlier stage of mid-life, older men in fact continue to experience their lives through the lens of gender, constructing their identities and narrations in gendered terms. Hurd Clarke (in press) notes that men in age continue to define their masculinity relationally, against the categories of women and gay men, both of which are positioned subordinately. Calasanti (2004) and Hurd Clarke and Korotchenko (2015) argue, furthermore, that men retain advantages in age that relate to and continue their earlier gender privileges, so that Sontag's analysis of the double standard in ageing still applies: 'men are "allowed" to age without penalty, in several ways that women are not' (1972: 31). For Thompson (2006: 634), 'lived masculinities are negotiated performances, that help maintain the gender scripts that are "out there" in culture, institutions, and in relationships, and reveal relations of dominance and subordination'. Gender norms, he suggests, continue to operate in age, and this is the case both in regard to evaluations (older men are deemed more intellectually competent and attractive than older women) and in their self-perceptions. Later-life scripts may thus be more uncertain, but they remain imbued with gender. Lodge and Umberson (2012) found that both gay and heterosexual mid-life men continued to frame their bodies as fundamentally different from women's. Both groups of men experienced ageing in terms of a decline in the body functionality, but whereas gay men often described the body's decline in age in terms of loss of appearance (which was often distressing), heterosexual men rarely referred to any such erosion. Parallel work on women (Lodge and Umberson, 2012) found little concern around bodily functionality in mid-life, but considerable concern around bodily appearance. As we shall see, echoes of this division were found in the two studies of dress.

\section{Dress and masculinities}

Fashion and dress is cultural territory linked with women and gay men, the two categories against which dominant hegemonic masculinity is constructed. As such, it is viewed with caution and some circumspection within mainstream masculinity (Barry and Phillips, 2016). Kaiser (2012) notes how the phenomenon of 
fashion is itself coded as feminine, to the extent that 'men's fashion' is framed as a contradictory space. These meanings are reflected in dress studies, which overwhelmingly focus on women. A glance at the lists of key publishers like Berg or Bloomsbury, or the articles in journals like Fashion Theory, or presentations at the Association of Dress Historians, or Handbooks (Barnard, 2007; Welters and Lillethun, 2011; Black et al., 2013) reveals this gender bias (though there have been some recent exceptions; McNeil and Karaminas, 2009). As a result, the field of fashion and dress presents an unusual situation in which women represent the implicit human norm, something usually accorded to men. There is a literature on masculinity and dress, but it is biased towards a limited set of topics: the transgressive, the subcultural, youth, high style, the dandy and the suit (Hebdige, 1979; Wilson, 1985; Edwards, 1997; Winge, 2003; Bennett, 2013; Barry and Martin, 2015; Breward, 2016; McCauley Bowstead, 2018). What is, as yet, missing is attention to the middle aged, the ordinary and mainstream: in other words, the men who buy their clothes from the high street, the supermarket and the internet, and whose engagement with fashion as a cultural field is limited, and indeed quite closely circumscribed. This is the sector, however, that provides the background for my study. Recently there has been some attention paid in cultural gerontology to questions of dress, appearance and age in relation to men (Sadkowska et al., 2016), but this has tended to focus on fashion-conscious men rather than the mainstream.

The norm that governs the mainstream response today is one of low engagement. It is important to note, however, that this has not always been the case. Elite men in the past were heavily involved in fashion and in elaborate display through dress; so much so, that the history of dress challenges any naturalisation of spectacular display in dress with female subjectivity. From the 14th century until the late 18th, elite men could be as colourful, flamboyant and sumptuously dressed as women. Ornate dress was a class rather than a gender prerogative. From the late 18th century onwards, men withdrew, adopting what Flügel (1930) termed the Great Masculine Renunciation, whereby men increasingly adopted dark, sober, plain forms of dress that allowed little for personal vanity or show, pursuing the more limited aims of dressing correctly or according to good taste. This is, of course, an oversimple account. There is evidence for enduring engagement with dress by men, with continuing interest in appearance and display evidenced not only in the macaroni and dandy (Breward, 1999, 2016; McNeil, 2000; Luckett, 2000; McNeil and Karaminas, 2009), but also in the historical narratives of ordinary men, as Ugolini's (2007) study of letters and diaries in the period 1880-1939 shows. Men remain interested in dress. This should not be surprising since dress is part of the presentation of self in everyday life, and as such of concern to all social actors. But interest by mainstream men is controlled and limited, contained within distinctive parameters. More recently, the phenomenon of metrosexual man may seem to challenge the predominant response of low interest; and there is certainly some evidence for greater engagement with fashion by younger men as part of the general expansion of consumption (Barry and Martin, 2015; Barry and Phillips, 2016; McCauley Bowstead, 2018). As we shall see, however, this has had only limited impact on my older respondents, who by and large carry into old age, the normative structures and meanings around dress they acquired when younger. 
Mainstream men's clothing in this cultural system is relatively stable, not subject to the vagaries of fashion, slow moving in its development, practical in its orientation, not subject to self-conscious appraisal. In this, it links to the dominant norm of hegemonic masculinity outlined by Connell. Here masculinity is assumed to be stable, innate, not consciously constructed - certainly not subject to the vagaries of fashion. This is reflected in the assumed relationship to dress (Crane, 2000). Conekin refers to an 'unacceptable contradiction ... Self consciousness is permissible, even attractive in a woman; it is perceived as weak and unmanly in a man' (quoted in McNeil and Karaminas, 2009: 429). The consequence of this is that men are set free to act and be, relatively unencumbered by self-consciousness. Their clothes achieve the status of the unmarked category, contrasting with women's heavily marked status (Kuchta, 2002; Kaiser, 2012). In Berger's (1972: 47) celebrated dictum, 'men act, and women appear'. This hegemonic gendered system of looking frees men from the sexualised gaze that women are subject to, and that plays a central part in the construction of the core values of fashion as a cultural ideal.

It also underpins the neutral, relatively unchanging, unthinking character of mainstream male dress. Mainstream male dress is dull - certainly by contrast to women's dress with its elaboration of styles, colours, fabrics - but it is a dullness that liberates men. Men's dress often contains an element of quasi uniform; and this once again underpins the way it remains relatively removed from comment or self-consciousness. This relates to a further feature of dominant male dress which is the way that it is close coded. Small details, in terms of buttons, quality of fabric, colour or cut, are significant, marking out social and cultural divisions, underpinning judgements made, particularly by fellow men who are closely attuned to these details.

Lastly, men's dress is more strongly imbued with ideas of power and authority. This is best expressed in the modern era by the suit, which has been subject to relatively developed literature (Harvey, 1995; Kuchta, 2002; Breward, 2016; Hollander, 2016). Functionality, status, power are all central themes of hegemonic masculinity, and reflected in formal male dress. Though erotic elements are not absent, they are muted, compared with their role in mainstream women's dress; and this had implications for how age is played out in this cultural field.

\section{Methods}

The article draws on two empirical studies. The first and earlier, funded by the Economic and Social Research Council, focused on the experiences and views of older women regarding dress, and the responses of the media and clothing industries. It was based on qualitative interviews, and was reported as Fashion and Age: Dress, the Body and Later Life (Twigg, 2013). This article centres on the second, parallel, study that focused on men, masculinity and age. This was based on qualitative interviews with 24 men based in Kent in the United Kingdom, an area bordering on London with mixed urban, suburban and semi-rural character. The men were recruited by a range of routes - local associations and clubs like Probus and the British Legion, newssheets, cards in shops, local councillors, community leaders - to produce a plurality of social backgrounds. The sample was selected to 
include 'ordinary' or 'mainstream' men aged 58-85 who expressed no particular interest in dress. The sample included men from both middle- and working-class occupations, broadly in the ratio two-thirds to one-third. However, many of the men had had varied employment careers that meant assigning them to one or other class was not easy. Three were in full-time work; six had some form of parttime employment. The sample was also structured to reflect sexuality as a potentially significant factor, with five gay men. The majority of men in the sample were partnered: one was single and two widowed. One respondent was English raised Afro-Caribbean; the remainder were white. The interviews were recorded and transcribed. They were analysed using traditional qualitative methods involving repeated readings, preparation of analytic résumés, systematic analysis of the narratives, identification of recurring themes and patterning, and interrogation and reinterrogation of these. The study was approved by the Ethics Committee of the University of Kent, and funded by the Leverhulme Trust.

This article is based on the second study, which explored the experiences of men, but at various points contrasts will be made with the earlier study of women, allowing for an exploration of the different ways dress operates in their lives, and suggesting some of the ways in which the experience of age is gendered.

\section{Dress and its relationship to age}

Most men in the study conformed to the predominant, mainstream norm of relative indifference. The majority did not see their dress through the lens of fashion; and the word was actively repudiated by some. This was in contrast with the earlier study of women (Twigg, 2013), where fashion was a widely acknowledged term; and one that resonated with the women's own experiences in relation to age. By contrast, the men's involvement was muted and low key. Trevor, a former police officer in his late fifties, explained how he and his friends gave clothes little thought:

I mean, in my little circle we tend to - you know, you don't even give it a second thought, really. You all tend to dress the same, you know, in a sense. I don't think it's a case of wanting to belong - you know, we all - it's just you tend to, you know, wear the same sort of stuff ... Don't think about it, I suppose.

Their comments expressed continuity with the dominant mainstream values of eschewing active interest, and of generally fitting in. They thus supported the wider view that later years, at least until the irruption of serious ill health, forms an extended arc of shared culture that bridges the passage from youth to entrenched old age (Öberg and Tornstam, 1999, 2001; Gilleard and Higgs, 2000, 2013; Jones et al., 2008).

The repudiation of fashion and its feminised values, however, did not mean that men were indifferent to dress. Gavin, a former stock trader (67), dressed in stylish but conventional clothes centred around a blazer and grey trousers. As he explained:

My normal garb if I'm going out somewhere smart will be a blazer and trousers. I used to listen to Alan Whicker because he travelled all over the place and met all sorts of people and he always used to say, 'With a blazer and a pair of grey slacks 
you can get in anywhere', and I think that's absolutely right and that sort of covers all possibilities. You can get away with it in a formal environment and an informal one as well. And if absolutely necessary, you can take your tie off, but you can put it back on again.

Dress was something he attended to, but within quite a narrow code. Clothes for him were important in conveying social standing and traditional masculine qualities of discernment and social authority:

I'm happier overdressed than underdressed ... If someone feels that I'm in charge because I'm better dressed or they're inferior, I don't mind that. I don't mind that. I mean it's not a nice thing to say, but I don't want to be the one who's scruffy in a smart environment.

There was, however, a distinctive group in the study who were more strongly engaged in dress, but this was through a concept of style rather than fashion. They had worked in the creative industries like photography, the media, architecture and design education; and for them style was a serious matter that related to their continuing identities as 'creatives'. All were heterosexual. Chris, who was in his eighties, had moved from London to a somewhat deprived seaside town, having worked as a photographic director in the media. In the interview, he wore the uniform of smart creatives in the form of fine black cords, a black under jersey, a pale grey sweater, with his silver hair brushed back from his face. He described the predominant style of most older people locally, but then linked his continued interest in style with the new, younger, more arts-oriented population in the town:

There's a lot of retired people, particularly around here, and they all buy their clothes in Marks \& Spencer, or probably their wives buy them, you know, and they're just sort of ordinary people. But there's a younger group here, very lively actually. So there's a kind of different vibe when it comes to the sort of people who go to art galleries and go to events, music events, and things like that. So yeah, there's quite a sharp cut-off.

Miles (67), who was an architect, dressed in a distinctive style of black suits and white shirts:

I would say I'm a careful dresser. And that's not unexpected in architects. I think architects generally are quite careful about the way they dress because it says in some ways, something about the way they design. And so there's something between style and lifestyle that comes through in the way that you dress. So, deliberate, and careful, perhaps.

As we shall see, this orientation to style, although not about age per se, interplayed with responses to it. It also contained a clearly classed aspect.

Detail in dress was important as a particular site for the exercise of individuality and discernment for this group. Owen, who was a press officer in his late fifties, 
explained how he might wear a conventional suit, but in a distinctive way that undercut its meaning:

So I would, kind of, not wear this suit to look like a banker, because it's a pinstripe suit. So I'd wear - I'd always wear a dark shirt with it to kind of be a bit different ... So I would not wear it ever with a white shirt. I might wear it with a black polo neck or something like that.

His account emphasised the significance of small twists, subversions, choices, acts of independence and flare that marked his dress out and enabled him to express his individuality in the context of the conventions of work.

This sense of the significance of small details was found also in the response of the more conventional, where to be dressed correctly was a key value. Graham, a former university librarian in his eighties, saw wearing the right clothes for the situation or setting as the key to being dressed well. Once that was settled, there was no need of further thought. Referring to the precepts of Beau Brummel, as befitted his background as a university librarian, he explained how 'you're supposed to dress so that it doesn't sort of show, you know'. Asked to say what his clothes might say about him, he responded 'Gosh ... Well, I'd hope they say I'm a sensible kind of - a sober educated man.' He was thus, like other conventionally dressed men, free to act unencumbered by issues of fashionability or style. But this did not mean he was uninterested in dress. He did think about clothes, but mostly in terms of small details and choices. These were occasions for discernment and for correctness in dress:

I do actually think about it. I do worry about fairly minor things, you know ... When I wear my brown shoes I'll wear the brown socks, or the fawn socks, with them. It doesn't really matter about these. But I'm a little bit fussy about it, you know, and I have had problems with socks.

He agreed he was particular:

Yes, yes, that's right. And the same with a tie, when I wear a tie, you know. You sort of think, well, this is a nice tie, but does it really go with this shirt, you know. I can waste a bit of time, you know, deciding on a - sometimes you should buy a shirt and a tie at the same time, but even when I've done, that I haven't always approved of it thereafter, you know.

What mattered was attention to small details that enabled him to be correctly dressed, but in a way that still allowed him to express something of himself. In this he conformed to the tradition of close coding that marks mainstream male dress.

\section{Too young: too old?}

In the earlier study of women, it was clear that many women's responses were caught between the twin avoidances of 'too young' or 'too old'; a finding also found in the work of Klepp and Storm-Mathisen (2005). These operated as 
powerful discursive constructions shaping choices in middle and later years. In particular, the category of 'too young' haunted women's responses, and underlay what I have termed the Changing Room Moment (Twigg, 2013). Here Sarah, a respondent in her late fifties, describes that moment:

I'm very sad, I'm very upset. I mean some of the styles are quite gorgeous and I'd love to be able to wear them ... When you're in the changing room and you see, oh goodness! Is that me? (laughter) And I just think, no no, I can't wear it any more. It's a lovely style, and I just can't wear it. I just feel very sad. And then I've got to look for something that's more appropriate for my age. (Twigg, 2013: 62)

Or as the editor of Vogue similarly remarked:

I've always loved those kind of vintage tea dresses and things, and suddenly I look really tragic in them now. But they're still in my wardrobe because I like the dresses. I won't get rid of them, because they're part of my identity as the person that always wore them. And it's hard really to confront those things that you can't wear. (Twigg, 2013: 62)

By contrast, none of the men spoke in these terms. They did not exhibit any of the same sense of exile, or sadness, or regret. Indeed, the men did not, by and large, see dress through the lens of age in the direct way that most women did. Many indeed denied that age was relevant at all. Aiden, a former diplomat (59), who dressed smartly in a relaxed upper middle-class style, asserted this view:

Interviewer: Do you ever think to yourself, $\mathrm{mmm}$, that's not so suitable for me now, I'm too old for that, or that age comes into your thoughts? Aiden: $\quad$ No, never.

Interviewer: Okay. So when you go to buy things, you simply buy them and you never say: this is for teenagers.

Aiden: I've never once had that cross my threshold ... I've never thought about it, no ... the clothes I buy in Brazil could equally be used by a 19 year old.

On the few occasions when respondents did articulate a sense of clothes that were 'too young', it was often in conjunction with the category of 'too silly'. As Gavin, the former stock trader, explained 'I wouldn't go to something like Mr Harry or whatever, or Zing Clothing'. He knew such clothes would make him look 'very silly indeed'. So the category of 'too young' was here imbued with a different feeling from how it was for many women: foolish and silly, rather than lovely and longed for.

In a similar way, a number of men mentioned items associated with younger men that they would never wear, like hoodies, trainers, jeans, but this was because they disliked them and regarded them with a degree of social contempt. Frank, a former paper mill worker in his seventies, articulated his dislike of young styles in a jovial way: 
Interviewer: So you don't think you'd ever think, oh that's okay, but it's not suitable for someone my age?

Frank: Never. The only, there is one thing I hate, I absolutely loathe them, these jeans that are so tight around these fella's legs, they're like tights. Now if jeans are that tight, that's not doing their legs any good 'cause it's putting pressure on their arteries and everything.

Interviewer: But that's a fashion. You think's horrible, is it?

Frank: I think it's detestable. No, I couldn't put up with that, it's not right, it doesn't look right, does it.

Young men's dress was thus not seen as something they desired, or felt excluded from; rather it was 'silly', or even 'detestable'. There was no sense of cultural exile. Age and dress instead were seen as linked to the positive values of discernment and sense. We shall return to this when we explore the ways dress can exemplify moral values.

In a similar way, the category of 'too old' that was present in the responses of some women in the earlier study, seemed to have less significance for the men. For women, 'too old' was associated with dress that was dowdy, frumpy, producing an overly aged appearance that assigned them to an older category than they felt was culturally necessary. Many were actively aware of the danger, and some were determined to resist it. The men did not express things in quite that way. For some, their dress might be traditional, or even old fashioned, but these were largely seen as positive virtues; and age of itself was not central to this categorisation.

There were, however, men in the study who did try to avoid too old a look, but this was often bound up with a new enjoyment of leisure post-retirement, and with it of more colourful clothes that were now permitted to men as part of the general shift to more casual dress (Horton et al., 2016). Jack, a former miner (76), noted with amusement how men, including himself, could now wear pink. Keith, who was a widower and former local government officer, particularly enjoyed colourful dress. On the day of the interview he was wearing a bright checked shirt in rose, blue and white with mid-blue trousers. He saw this as part of keeping positive:

You don't have to think, right, I'm coming up to 70 now, I've got to ditch these bright shirts because people expect this of me. I don't want to feel people expect me because I'm getting older to down-dress, shall we say. I've got a very youthful outlook and I'll dress as if I'm younger. And I enjoy it. And as I say, I get a bit concerned when I - yes, we're all going to get old. I hope I stay healthy and hearty.

He had suffered bouts of depression in the past, and had lost his wife who had been active in his choice of clothes:

I've been very pessimistic during my life, but I now realise that I'm a fighter, 'cause I wanted to get over it. Yeah, as you say, it [his wife's sudden death] does affect me, even when thinking or talking about it, but I suppose it's all part of respect to Sue. She's probably looking down at me, thinking, at least you're still dressing properly. So I do - dressing is all sort of part of my lifestyle. I eat well and I look after myself, 
I keep the house in good order, so it's all part of my life. And I know I'm getting older, and none of us like getting older. But it's all part of self-respect and maintaining what I call a comfortable lifestyle.

The quotation points to the way engagement with dress, particularly colourful casual dress, could be part of maintaining a positive attitude, a form of self-respect, in the face of the potential erosions of age. It was about keeping upbeat, not allowing oneself to slip into negativity, associated here with dull, dingy dress. This was what was significant, rather than an attempt to resist age coding as such.

\section{Dress as moral engagement}

As Entwistle (2000) notes, dress is often spoken of in moral terms - good, bad, flawless - pointing to wider social values. For some of the men in the study, their clothes were indeed seen in those terms, expressing and upholding old-fashioned values. The link between old-fashioned dress and old-fashioned values was well illustrated in Henry. He had been long established in Kent, having been to the local public school, followed by working in the family firm of agricultural suppliers, though following the collapse of the firm, he had had a mixed career of working in fitted kitchens and debt collecting. He remained, however, a well-established figure locally. In his midseventies, he belonged to a generation accustomed to male sociability and its expression through dress. In general, clothes meant little directly to him. He did not think much about them, and his comments in the interview made no direct link to questions of age. He did not feel he dressed differently from when younger, and his account shows him wearing the same clothes over long periods, underscoring the slow fashion cycle that characterises traditional men's dress. For him it was a question of: 'conforming to who I'm with at the time'. At meetings of Probus (the senior version of Rotary) he would wear a club tie: 'People always wear that sort of thing. It's sort of - you would feel uncomfortable if you weren't dressed like that, put it that way.' For him clothes represented old-fashioned values, not just in their expression but their concrete materiality. He cited the virtues of well-made shoes that fit and last; and in his account, he added a second layer of value, through the fact that these were British-made.

Hotter shoes, they wear extremely well. I mean, the ones I wear - I've got a pair which are still useable, must be 20 years old plus, and they're still going strong, and they just don't wear out. You pay, you know, 70, 80 quid for them, but by golly, they last and last and last. And they're British, made in Britain.

\section{Quality is what matters:}

When I was growing up, my father always made sure, he was a great believer in you buy things of top quality and it'll last for years. I mean, for instance, I've still got a grey suit upstairs, which - it doesn't really fit me now, but I had that when I was $17,18 \ldots$ I wore it right through until last five years at times, funerals and things like that. It was the grey suit for that purpose. And same with shoes, I've got shoes up there, Veltshoen, beautifully made shoes, goodness knows what they'd cost today. 
He commended the old-fashioned service of a shop he patronised - the way the staff knew their stock and assisted in a professional way. Dress for him was, thus, embedded in ideas of quality, tradition and service. These clothes spoke to enduring values; they repudiated a trivial, ever-changing, throw-away society. Their continuing quality gave endorsement to him as an older man, expressing something of his placement within the locality and his life.

Traditional values could also be expressed in terms of tidiness and self-respect in dress. Frank (74), who had been in the Royal Air Force for the early part of his career, followed by work as a supervisor in a paper mill, had a clear sense of the relationship of dress to wider standards:

I like to be tidy ... I think if you're in that sort of position [supervisor] then you should dress appropriately. Now that might be old hat now, I mean I don't know.

He disliked what he saw as the scruffy, untidy presentation of the young:

you've only got to see the students down here when they come, and you look at them, they've got holes there, holes there, holes there, and that's the lads (both laugh). It's awful. They've got no pride, they don't give a damn what they look like.

He was a jovial man, and these comments were not made in a hostile way, but for him and many in the study, maintaining standards of dress was a matter of pride, rooted in a sense of generational experience, and as such a positive element in his identity as an older man.

Wearing the correct dress for the occasion could also be a moral act, a matter of showing respect for others. Aiden, as a former member of the diplomatic corps, had had a lifetime of dress codes. Personally he disliked suits, but he knew that there were circumstances that required formality in order to show proper respect: for example at meetings of the local council where he was an elected representative, he explained 'I'd be respectful, put on a tie or a jacket.' He was a Conservative member in a socially mixed authority, and his comments contained a slight sense that older and less socially elite councillors were not exactly of his social class, but that it was important to show respect for them and for the social institutions of democracy. Jack, the former miner from an opposite political position, made the same point:

if I was going to a parish council meeting, I'd wear a tie. I think I would anyway, you know. It's something that I'd just do ... I think it's just keeping up standards really, you know ... I don't know whether it's because most of the people would be senior - when I first joined the parish council, most of the people were senior to me and the men always turned up in ties, so I just did.

Correctness in dress was thus seen as part of a wider moral engagement.

It is important to recognise that age is not the sole, or even most, significant variable here, and that it intersects with cultural categories, such as class, status, gender, sexuality, as well as other more micro social distinctions. Clothing styles are nuanced in their reflection of this. This was particularly notable in the 
style-oriented group. Dress for the style-oriented men allowed for the assertion of another form of masculinity that expressed discernment, distinction, separation from the herd. Miles, the architect, for example, wore distinctive, expensive clothes by, for example, Issey Miyaki or Margaret Howell, that expressed high design values, albeit in a discrete way. He was adamant in rejecting the kinds of clothes that he saw as marketed at his age group:

I know what's advertised in The Telegraph, I know what I should be wearing for my age and I've very conscious of that, in the chinos, the cotton chinos and all the rest of it, but they just aren't for me.

He expanded on this:

And so you won't be disappointed to hear me say that I think these are aimed at older people. And there's a distinction between dressing - I think there's a distinction - I'm thinking on my feet now, of dressing classically and dressing young. I don't think this (pointing to his clothes) is necessarily young ... it's slightly ageless, isn't it? I think, so it's something to do with that style-lifestyle thing, not style-fashion style, but how you live your life and who you are.

His emphasis on the quality of design and on the role of discernment were very much the product of his particular professional and class position. At the same time, they did relate to age in that they enabled him to stave off the erosions of age and to continue to perform a powerful form of middle-class, professional masculinity.

Sexuality is widely assumed to be relevant to dress (Crane, 2000; Entwistle, 2000). In particular, there are widespread cultural expectations that gay men will be more engaged in fashion (Tuncay and Otnes, 2008), and the study included a sub-sample of five gay men to reflect this. It was not the case, however, that they presented a unified response. The linkages between age and sexuality did not work in an undifferentiated way. Howard, a gay former businessman, for example, showed me racks of showy, brightly coloured suits and jackets in, for example, banana yellow silk, brown brocade or bold chalk stripes. Aiden, the former diplomat, by contrast wore standard upper middle-class casual clothes, and I only became aware of his sexuality when he commented on himself as a gay man. Andy, who was a cinema usher, wore scruffy casual clothes that sent no specific message about sexuality, though he was actively involved in fantasy and crossdressing in his leisure time. The others also dressed distinctively, and in ways that linked to their gay identities, but there was no uniform response, nor did age operate in their accounts in a distinctive or unitary way. Their comments linked them as much to particular heterosexual men in the study, with whom they shared responses, as to other gay men. This group will be the subject of a further article.

\section{Gendered body in age}

The focus of the interviews was dress, and that is what the men were primarily asked to talk about. But one cannot explore clothing without referring to the 
body that wears it, and gives it life (Entwistle, 2000). In general, the interviews with men articulated less concern over bodily change than had the women's (Twigg, 2013). This reflects the way that women's dress tends to be more body focused and exposing, with a closer fit and more in the way of visible flesh. The youthful ideal also operates more powerfully in women's dress, lying at the ideological centre of the Fashion System. These gendered patterns are part of wider culture of the body in which youthful appearance norms act powerfully on women, as evidenced in a range of work on hair, facial appearance, cosmetic surgery and anti-ageing interventions generally (Davis, 1995; Katz, 2001; Katz and Marshall, 2003; Hurd Clarke, 2011; Lodge and Umberson, 2012; Marshall, 2015; Ward, 2015; Ojala et al., 2016). The embodied appearance of age and its implications for dress were, thus, a more significant element in the women's narrations.

Some of the men, however, did refer directly to changes in the body with age. Trevor, a former police officer, referred ruefully to clothes that 'shrink in the wardrobe'. For most, it was a fairly minor matter of collar sizes - with age they had had to move up a size or two to accommodate spreading necks - or the cut of shirts, with a need to avoid slim-fit. By and large they accepted the situation with good grace. But the one point where body change did touch a nerve was my interview prompt concerning elastic in waists. This was met with cries of derision. Trevor, the former police officer, cried: 'no, no!' 'That's anathema' said Tony, the former graphic designer. Chris held up his fingers crossed, as if to ward off a vampire. Aiden, the former diplomat, described it as:

horrible ... I mean, you really have lost the plot as you start going to elastics. I think you've given up the ghost then.

There was clearly something about what elastic signalled that alarmed the respondents and shook them out of their dominant response that age was not relevant. Elastic seems to signal to the world that it was indeed relevant. It is noteable, however, that these respondents were relatively young, in their late fifties and sixties. Some of the changes in physique that can come with age had not yet impacted on them, though the fear of them was clearly present. Graham, the former university librarian in his eighties, had, by contrast, had to face some disquieting changes:

what distresses me a bit ... is the fact that, I mean, I always used to be very thin and now I seem to have got this sort of - you know, a bit of a paunch here, you know (laughter), which I try and pretend isn't there, but my wife's always telling me it is there, you know ... So I look at other people maybe the same shape as me and think, gosh, he's a bit fat, and then my wife's like, 'Well, you're just as bad', you know.

Most of the men in the study accepted some weight gain as an inevitable part of ageing. But Tony (66) found it directly distressing, and something he wanted to escape from. He was a graphic designer who had taught in art colleges, but regarded himself primarily as an artist. He loved exciting, interesting clothes, recalling with affection his Bowie-inspired outfits, his yellow snakeskin boots and leopard-skin brothel creepers (worn for his wedding). Keith Richards and Johnny Cash were 
continuing influences in his style. But weight gain after retirement had caused him considerable distress:

(Sighs) I have a lot of clothes that no longer fit me (laughs). And I regret that because I have some really lovely clothes and I can't put them on anymore. So they're in a wardrobe in the attic ... I've put weight on. I've put most weight on since I've retired.

His comments were focused on weight gain, and the desire to lose it so as to recover the person he felt he really was. To this degree, his comments were in line with many who gain weight. But they also contained a response to ageing; and this underlay a sense of sadness in his narrative:

Tony: There are clothes I would love to wear again, yeah. And also it's, I'm not quite sure how to phrase this ... I want to look my age. I mean, my mental age. I want to look younger and I think I don't look younger if I'm overweight, so if I lose weight I think I can...

Interviewer: You'll look more like the person you feel yourself to be?

Tony: $\quad$ Yeah, yeah. Yeah, 'cause I have a kind of ideal me in my head and I've kind of stepped out of that recently (laughs).

Interviewer: Okay. And that ideal you is, what?

Tony: $\quad$ Erm, well, my mind I think is about 35. I think visually my ideal me was probably 45 , actually. So, slightly different.

Interviewer: And would that ideal you be dressed differently from the way you dress now?

Tony: No, no. I think they just look better because I don't have muffin top.

Tony was unusual in expressing directly the desire to look younger, something he identifies strongly with his 'mental age', which for him represented his 'real' age. Weight gain had cut him off from this.

For some, however, changes in the body were more openly linked to age and to a feared future of decline, through the spectre of dereliction. Alan, a retired research scientist in his late seventies, described the fate of men who neglected themselves:

I have to say though that I have seen some men, you know, not naming any names or any situations, but when their wife dies they do tend to become a little bit like an old badger. Some of them sadly don't always wash their underwear or change it as frequently as they should, and there is a definite aroma about them. I play bridge a lot, so there are one or two blokes who you know when you sit down at the table with them, there will be a sort of a slight smell of dank clothes.

He identified this with the absence of a wife:

I think some men need a wife to keep them up to the mark. I think some men need a wife to tell them when to change their clothes or wash their clothes, clean the house, a shirt. I mean there's one guy, you know, on Friday, nice 
chap, he had a career, but talking to him, although he was wearing a jacket and a buttoned-up shirt, so from a distance he looked quite formal, he was in his eighties, but when you got up close he had food stains all the way down and you thought, oh, you know, and I could never go out like that. But I think my wife would probably feel it reflected on her as well.

It is notable in his narrative that he sees the care of the body as a gendered responsibility that rests with women. This danger of dereliction is a subject he returned to three times in the interview, and it clearly represented a form of feared future. Jack, a former miner, similarly expressed his dislike for undignified dereliction in dress and appearance. A community-oriented man, he saw this in terms of the loss of respect:

I can't explain it, really, but I can only speak from my own experience. My grandkids would say to me - they look up to me and they respect me, and I did my grandparents and parents and that, you know what I mean? And I always like them to look nice, you know what I mean, to be presentable. And I think my grandkids are the same with me. They wouldn't want to see me going round, you know, casual and not caring, or not worrying about the way I dress and all that. Because they've got that much respect for me, I don't think they would allow me to be like that.

One or two of the men had, indeed, more or less given up, not to the extent described by Alan, but certainly in contrast to their younger selves. This was often rooted in the ways in which their bodies had declined under the impact of ill health. Guy, who was gay, had been an actor, then working in retail, and subsequently in call centres. Earlier in his life he had relished elegant suits and, like many who work in retail, had internalised the sense that good clothes were expensive clothes. But now 85 and living on a low income, with health problems and a figure that was no longer slim or well defined, he had abandoned any attempt to maintain his appearance. His interview was marked by sense of negativity, pointlessness and irritation with his life:

I like expensive clothes, but I can't possibly afford the, you know, the expensive casual clothes that you see in magazines and stuff. And I don't go anywhere to - if I had them I wouldn't go anywhere, I mean, where do you go in [low-income seaside suburban settlement]? Nowhere. Sort of geriatricsville again isn't it. Next time the ... next door to the Crem isn't it (both laugh), next stop the Crem.

Overall, there was a contrast in the men's responses to those of the women's. There was not the same preoccupation in the men's narratives with the ways certain styles no longer suited, or exposed the aged body in ways that were unflattering or that underwrote a contrast between the youthful expectations that underlay the styles, and the aged body on show. For men, the point at which age really began to impact seemed to be later. Echoing Lodge and Umberson's (2012, 2013) analysis, questions of age, embodiment and appearance were less significant for them - at least until the point when more serious bodily decline set in. 


\section{Conclusion}

The article has explored the role of dress in the constitution of embodied masculinity in age. Four features of the responses of the men stood out. The first related to integration. The overall sense of the interviews was one of continuity, with attitudes to dress not greatly different from the bulk of mainstream masculinity. The dominant norm remained one of low engagement, with older men's dress sharing the relatively unchanging, unreflective character of mainstream menswear, although combined with a continuing concern with aspects of dress as part of the microsocial order, evidenced in the enduring interest in close coding that characterises much masculine dress. This pattern supports the more general argument within cultural gerontology that later-life today needs to be seen as part of an extended arc of middle years that is not broken until the irruption of serious ill health, a pattern reinforced by the spread of mass consumption to older cohorts. Within the cohort studied, however, there were cultural differences, with distinctive attitudes towards the nuances of dress and the values they expressed. For example, the group who identified as 'creatives' dressed in a self-consciously distinctive way, and wished to continue doing so in later years. Their adoption of stylish dress represented a continuity of visual engagement that was part of their identity. It was this, rather than any explicit extension of the values of Metrosexual Man to older cohorts, that underlay their response.

Secondly, men's dress is less age-differentiated than women's. Age was in general not central to the men's accounts; and certainly not as central as it had been to those of many women in the earlier study. Some, indeed, denied that they thought in terms of age at all, and continued to wear the same clothes as earlier. There was no great sense of a barrier to what they might wear, or of imposed changes with age. There were some differences that resulted from alterations in lifestyle associated with retirement, particularly for middle-class men who were no longer required to wear formal clothes on a daily basis, but these mostly involved greater, rather than less, integration with the mainstream through the adoption of casual dress. The idea of clothes that could be 'too young', that haunted the responses of many of the women, had limited significance for them. If there was such a category as 'too young', it was often linked to 'too silly' or some other derogatory term. There was not the sense of cultural exile that had marked comments of the women with their accounts of the Changing Room Moment. Nor did the category of 'too old' mean much to these men. For some, indeed, old-fashioned dress denoted positive values related to age.

Thirdly, dress could represent a positive moral realm in the lives of these men, though largely in an implicitly, muted and taken-for-granted way that was wholly unrelated to fashion. There were distinctive meanings attached to dress that expressed the values of the older man. Age, here, was linked to good sense and discernment. Dress could also express what were seen as distinctly old-fashioned values in relation to neatness and order, or to proper respect. Responses displayed a clear sense of the moral meanings of dress, the importance of wearing the right clothes for the occasion, and the ways this could express support for the collective values of an institution or social setting. Old-fashioned clothes could, thus, be a way of expressing both enduring values and qualities of worth, repudiating the cheap 
throw-away aspects of modern culture, and an implicit endorsement of the older self as of continuing value. These were not views that were expressed in the women's interviews. They underwrote a sense that masculinity in age retains positive value, in a way that was not the case in relation to women.

Fourthly, dress reveals ways in which masculinity in age retains greater positivity than is the case with women. This links to wider arguments, presented by Sontag (1972), Calasanti (2004), Hurd Clarke (2011) and others, that men in age retain gender privilege. In the case of dress, part of that gender privilege is the ability not to be drawn into the pervasive discourse of erosion that marked the women's responses. Women engage with the erosive discourses of age and appearance much younger than men. Their dress contains a stronger element of erotic display, and is linked to a wider gendered culture of bodily perfectionism, reflected in the youthful ideal. Dress for women is, thus, part of a larger issue of appearance and concern over the loss of youthful attractiveness. For men, by contrast, dress predominantly has other meanings, linked to authority, social status and the ability to fit in. Age did, however, impact on the men, but at a later stage. Dress and age began to be linked negatively when the spectre of dereliction came into view. This reflected the way masculinity is not centrally about being looked at, being subject to the sexualised gaze, but is much more connected to issues of power, authority, physical strength and virility. These can be expressed through dress, but in ways that are not disrupted by age to quite the degree that is the case with women. Threats to embodiment for men in age focus around the body of health, strength and potency, rather than the body of sexual display. The point of threat, therefore, comes with the spectre of dereliction, decline and neglect.

Acknowledgement. I am grateful to the Leverhulme Trust for funding this study.

Financial support. This work was supported by the Leverhulme Trust (grant number RF-2015-383).

Ethical standards. The study was approved by the Ethics Committee of the University of Kent SRCEA 145.

\section{References}

Barnard M (ed.) (2007) Fashion Theory: A Reader. London: Routledge.

Bartky SL (1999) Unplanned obsolescence: some reflections in aging. In Walker MU (ed.), Mother Time: Women, Ageing and Ethics. Boulder, CO: Rowman \& Littlefield, pp. 61-74.

Barry B and Martin D (2015) Dapper dudes: young men's fashion consumption and expressions of masculinity. Critical Studies in Men's Fashion 2, 5-21.

Barry B and Phillips BJ (2016) The fashion engagement grid: understanding men's responses to fashion advertising. International Journal of Advertising 35, 438-464.

Bennett A (2013) Music, Style and Aging: Growing Old Disgracefully. Philadelphia, PA: Temple University Press.

Berger J (1972) Ways of Seeing. London: Penguin.

Black S, de la Haye A, Entwistle J, Rocamora A, Root RA and Thomas H (2013) The Handbook of Fashion Studies. London: Bloomsbury.

Breward C (1999) The Hidden Consumer: Masculinities, Fashion and City Life, 1860-1914. Manchester, UK: Manchester University Press.

Breward C (2016) The Suit: Form, Function and Style. London: Reaktion Books.

Buse C and Twigg J (2014) Women with dementia and their handbags: negotiating identity, privacy and 'home' through material culture. Journal of Aging Studies 30, 14-22. 
Buse C, Martin D and Nettleton S (2018) Conceptualising 'materialities of care': making visible mundane material culture in health and social care contexts. Sociology of Health and Illness 40, 243-255.

Calasanti T (2004) Feminist gerontology and old men. Journals of Gerontology: Psychological Sciences and Social Sciences 59B, S305-S314.

Calasanti T and King N (2005) Firming the floppy penis: age, class and gender relations in the lives of old men. Men and Masculinities 8, 3-23.

Calasanti T and King $\mathbf{N}$ (2007) 'Beware the estrogen assault': ideals of old manhood in anti aging advertisements. Journal of Aging Studies 21, 357-368.

Calasanti T, Pietila I, Ojala H and King N (2013) Men, bodily control and health behaviours: the importance of age. Health Psychology 32, 15-23.

Connell RW (1995) Masculinities. Cambridge: Polity.

Connell RW and Messerschmidt JW (2005) Hegemonic masculinity: rethinking the concept. Gender \& Society 19, 829-859.

Crane D (2000) Fashion and its Social Agendas: Class, Gender and Identity in Clothing. Chicago, IL: University of Chicago Press.

Davis K (1995) Reshaping the Female Body: The Dilemma of Cosmetic Surgery. London: Routledge.

Drummond MJN (2003) Retired men, retired bodies. International Journal of Men's Health 2, 183-199.

Edwards T (1997) Men in the Mirror: Men's Fashion, Masculinity and Consumer Society. London: Cassell.

Ekerdt DJ (2009) Dispossession: the tenacity of things. In Jones IR, Higgs P and Ekerdt DJ (eds), Consumption and Generational Change: The Rise of Consumer Lifestyles and the Transformation of Later Life. New Brunswick, NJ: Transaction Books, pp. 63-80.

Ekerdt DJ (2015) Possessions as a material convoy. In Twigg J and Martin W (eds), The Routledge Handbook of Cultural Gerontology. London: Routledge, pp. 305-320.

Entwistle J (2000) The Fashioned Body: Fashion, Dress and Modern Social Theory. Cambridge: Polity.

Flügel JC (1930) The Psychology of Clothes. London: Hogarth Press.

Friedan B (1993) The Fountain of Age. London: Vintage.

Furman FK (1997) Facing the Mirror: Older Women and Beauty Shop Culture. New York, NY: Routledge.

Furman FK (1999) There are no old Venuses: older women's responses to their aging bodies. In Walker MU (ed.), Mother Time: Women, Aging and Ethics. Boulder, CO: Rowman \& Littlefield, pp. $7-22$.

Gilleard C and Higgs P (2000) Cultures of Ageing: Self, Citizen and the Body. London: Prentice Hall.

Gilleard C and Higgs P (2013) Ageing, Corporeality and Embodiment. London: Anthem Press.

Ginn J and Arber S (1995) Connecting Gender and Ageing: A Sociological Approach. Milton Keynes, UK: Open University.

Greer G (1991) The Change: Women, Ageing and the Menopause. London: Hamish Hamilton.

Gullette MM (2011) Agewise: Fighting the New Ageism in America. Chicago, IL: University of Chicago.

Guy A, Green E and Banim M (2001) Introduction. In Guy A, Green E and Banim M (eds), Through the Wardrobe: Women's Relationships with Their Clothes. Oxford: Berg, pp. 1-17.

Harvey J (1995) Men in Black. London: Reaktion Books.

Hazan H (1994) Old Age: Constructions and Deconstructions. Cambridge: Cambridge University Press.

Hearn J (1995) Imagining the ageing of men. In Featherstone M and Wernick A. (eds), Images of Ageing: Cultural Representations of Later Life. London: Routledge, pp. 97-118.

Hearn J and Wray S (2015) Gender: impactions of a contested area. In Twigg J and Martin W (eds), The Routledge Handbook of Cultural Gerontology. London: Routledge, pp. 201-209.

Hebdige D (1979) Subculture: The Meaning of Style. London: Methuen.

Hird MJ (2004) Feminist matters: new materialist considerations of sexual difference. Feminist Theory 2, 223-232.

Hollander A (2016) Sex and Suits: The Evolution of Modern Dress. London: Bloomsbury.

Hoonaard DK van den (2007) Ageing and masculinity: a topic whose time has come. Journal of Ageing Studies 21, 277-280.

Horton K, Ferrero-Regis T and Payne A (2016) The hard work of leisure: healthy life, activewear and Lorna Jane. Annals of Leisure Research 19, 180-193.

Hurd Clarke L (2011) Facing Age: Women Growing Older in Anti-aging Culture. Lanham, MD: Rowman \& Littlefield. 
Hurd Clarke L (in press) Men and aging: perceptions and experiences of growing older in everyday life. Journal of Ageing Studies. https://doi.org/10.1016/j.jaging.2018.01.003

Hurd Clarke L, Bennett EV and Liu C (2014) Aging and masculinity: portrayals in men's magazines. Journal of Aging Studies 31, 26-33.

Hurd Clarke L and Korotchenko A (2015) 'I know it exists ... but I haven't experienced it personally': older Canadian men's perceptions of ageism as a distant problem. Ageing \& Society 36, 1757-1773.

Jackson D (2016) Exploring Ageing Masculinities: The Body, Sexuality and Social Lives. London: Palgrave.

Jones IR, Hyde M, Victor CR, Wiggins RD, Gilleard C and Higgs P (2008) Ageing in a Consumer Society: From Passive to Active Consumption in Britain. Bristol, UK: Policy Press.

Jones J and Pugh S (2005) Ageing gay men: lessons from the sociology of embodiment. Men and Masculinities 7, 248-260.

Kaiser SB (2012) Fashion and Cultural Studies. London: Berg.

Katz S (2001) Growing older without aging? Positive aging, anti-ageism, and anti-aging. Generations 2732.

Katz S and Marshall B (2003) New sex for old: lifestyle, consumerism and the ethics of aging well. Journal of Aging Studies 17, 3-16.

Klepp GI and Storm-Mathisen A (2005) Reading fashion as age: teenage girls' and grown women's accounts of clothing as body and social status. Fashion Theory 9, 323-342.

Küchler S and Miller D (eds) (2005) Clothing as Material Culture. Oxford: Berg.

Kuchta D (2002) The Three-piece Suit and Modern Masculinity, England, 1550-1850. Berkeley, CA: University of California Press.

Lodge AC and Umberson D (2012) All shook up: sexuality of the mid to later life married couple. Journal of Marriage and the Family 74, 428-443.

Lodge AC and Umberson D (2013) Age and embodied masculinities: midlife gay and heterosexual men talk about their bodies. Journal of Ageing Studies 27, 225-232.

Luckett M (2000) Performing masculinities: dandyism and male fashion in 1960s and 70s in British cinema. In Bruzzi S and Gibson PC (eds), Fashion Cultures: Theories, Explorations and Analyses. London: Routledge, pp. 315-328.

Marshall B (2015) Anti-ageing and identities. In Twigg J and Martin W (eds), The Routledge Handbook of Cultural Gerontology. London: Routledge, pp. 141-156.

Marshall BL and Katz S (2002) Forever functional: sexual fitness and the aging male body. Body and Society 8, 4, 43-70.

McCauley Bowstead J (2018) Menswear Revolution: The Transformation of Contemporary Men's Fashion. London: Bloomsbury.

McNeil P (2000) Macaroni masculinities. Fashion Theory 4, 373-404.

McNeil P and Karaminas V (eds) (2009) The Men's Fashion Reader. Oxford: Berg.

Öberg P and Tornstam L (1999) Body images among men and women of different ages. Ageing \& Society 19, 629-644.

Öberg P and Tornstam L (2001) Youthfulness and fitness - identity ideals for all ages? Journal of Ageing and Identity 6, 15-29.

Ojala H, Calasanti T, King N and Pietilä I (2016) Natural(ly) men: masculinity and gendered anti-ageing practices in Finland and the USA. Ageing \& Society 36, 356-375.

Pietiä I and Ojala H (2011) Acting age in the context of health: middle-aged working-class men talking about bodies and aging. Journal of Aging Studies 25, 380-389.

Sadkowska AM, Wilde DJ and Fisher T (2016) Third age men's experiences of fashion and clothing: phenomenological analysis. Age Culture Humanities 2, 35-70.

Sandberg L (2011) Getting Intimate: A Feminist Analysis of Old Age, Masculinity and Sexuality. Linköping, Sweden: Linköping Studies in Arts and Sciences.

Simpson P (2013a) Work that body: distinguishing an authentic middle aged gay self. Critical Studies in Fashion and Beauty 4, 147-171.

Simpson P (2013b) Alienation, ambivalence and agency: middle aged gay men and ageism in Manchester's gay village. Sexualities 16, 283-299.

Slevin KF (2008) Disciplining bodies: the ageing experiences of older heterosexual and gay men. Generations, Spring.

Smith GV and Ekerdt D (2011) Confronting the material convoy in later life. Sociological Inquiry 81, 377-391. 
Sontag S (1972) The double standard of aging. The Saturday Review, 23 September, 29-38.

Spector-Mersel G (2006) Never-ageing scripts: western hegemonic masculinity scripts. Journal of Gender Studies 15, 67-82.

Tarrant A (2010) Maturing a sub discipline: the intersectional geographies of masculinities and old age. Geography Compass 4, 1580-1591.

Thompson EH (1994) Older Men's Lives. Thousand Oaks, CA: Sage.

Thompson EH (2006) Images of old men's masculinity: still a man? Sex Roles 55, 633-648.

Tseëlon E (1995) The Masque of Femininity. London: Sage.

Tuncay $\mathbf{L}$ and Otnes CC (2008) The use of persuasion management strategies by identity vulnerable consumers: the case of urban heterosexual male shoppers. Journal of Retailing 84, 487-499.

Twigg J (2004) The body, gender and age: feminist insights in social gerontology. Journal of Aging Studies 18, 59-73.

Twigg J (2013) Fashion and Age: Dress, the Body and Later Life. London: Bloomsbury.

Twigg J and Martin W (eds) (2015) The Routledge Handbook of Cultural Gerontology. London: Routledge.

Ugolini L (2007) Men and Menswear: Sartorial Consumption in Britain 1880-1939. Aldershot, UK: Ashgate.

Ward R (2015) Hair and age. In Twigg J and Martin W (eds), The Routledge Handbook of Cultural Gerontology. London: Routledge, pp. 141-156.

Weber S and Mitchell C (eds) (2004) Not Just Any Dress: Narratives of Memory, Body, and Identity. New York: Peter Lang.

Welters L and Lillethun A (eds) (2011) The Fashion Reader. London: Bloomsbury.

Wilson E (1985) Adorned in Dreams: Fashion and Modernity. London: Virago.

Woodward K (ed.) (1999) Figuring Age: Women, Bodies, Generations. Bloomington, IN: Indiana University Press.

Cite this article: Twigg J (2020). Dress, gender and the embodiment of age: men and masculinities. Ageing \& Society 40, 105-125. https://doi.org/10.1017/S0144686X18000892 